\title{
Pharmacological challenge with a serotonin ID agonist in alcohol dependence
}

\author{
Bavanisha Vythilingum *1, Charmaine J Hugo ${ }^{1}$, J Stefan Maritz ${ }^{3}$, \\ Willie Pienaar ${ }^{2}$ and Dan J Stein ${ }^{1}$
}

\author{
Address: ${ }^{1}$ MRC Unit on Anxiety and Stress Disorders, Dept of Psychiatry University of Stellenbosch, South Africa, ${ }^{2}$ Dept of Psychiatry, University \\ of Stellenbosch, South Africa and ${ }^{3}$ Biostatistics Unit, Medical Research Council of South Africa \\ Email: Bavanisha Vythilingum* - bv@sun.ac.za; Charmaine J Hugo - cjhugo@sun.ac.za; J Stefan Maritz - stefan.maritz@mrc.ac.za; \\ Willie Pienaar - wppien@sun.ac.za; Dan J Stein - djs2@sun.ac.za \\ * Corresponding author
}

Published: 24 August 2005

BMC Psychiatry 2005, 5:31 doi:10.1186/147/-244X-5-31
Received: 04 May 2005

Accepted: 24 August 2005

This article is available from: http://www.biomedcentral.com/l47I-244X/5/3I

(c) 2005 Vythilingum et al; licensee BioMed Central Ltd.

This is an Open Access article distributed under the terms of the Creative Commons Attribution License (http://creativecommons.org/licenses/by/2.0), which permits unrestricted use, distribution, and reproduction in any medium, provided the original work is properly cited.

\begin{abstract}
Background: Both animal and clinical studies have implicated serotonergic dysfunction in the pathogenesis of alcohol abuse and dependence. However the exact mechanisms involved remain unknown. Theoretically, low serotonin promotes alcohol seeking behavior. Sumatriptan is a serotoninID agonist. It is postulated that sumatriptan's agonism at this terminal autoreceptor increases negative feedback, creating a net effect of decreased serotonergic neurotransmission. Administration of sumatriptan should therefore produce a craving for alcohol and the desire to drink.
\end{abstract}

Methods: Fifteen patients with alcohol dependence who had undergone detoxification were recruited. Sumatriptan $(100 \mathrm{mg})$ and placebo was administered in cross-over fashion on 2 separate days 72 hours apart. Both patients and raters were blind to all treatments.

Patients were assessed on the following scales at -30, 0, 30, 90, 150 and 210 minutes: A 6-item scale designed to rate the patient's intention to drink; The Sensation Scale; a I3-item affect analog scale designed to rate the pattern and extent of emotional changes; and an 8-item scale designed to rate the patient's craving for alcohol

Results: No significant differences were found between the placebo and sumatriptan groups and no significant cross over effects were found.

Conclusion: The general lack of efficacy of sumatriptan in producing alcohol-like symptoms or a desire to drink alcohol may suggest that the 5HTID receptor plays little role in the pathophysiology of alcoholism.

\section{Background}

Both animal and clinical studies have implicated serotonergic dysfunction in the pathogenesis of alcohol abuse and dependence $[1,2]$. However the exact mechanisms involved remain unknown. Pharmacological challenge studies provide one way of identifying the specific receptor systems involved.

Serotonergic dysfunction is thought particularly to be involved in alcohol craving. Verheul et al [3] proposed 
three types of craving - reward craving, relief craving and obsessive craving. Obsessive craving is defined as the loss of control over intrusive thoughts about alcohol and is believed to be mediated by a deficit of serotonin.

$\mathrm{m}$-chlorophenylpiperazine ( $\mathrm{m}$-CPP) is a serotonin agonist with actions at 5-HT1a, 5-HT1d, 5-HT2c receptors. The 5HT1a and 5HT1d receptors are autoreceptors and agonism here has been demonstrated to decrease net serotonergic transmission.[4] $\mathrm{m}$-CPP has been reported to elicit craving for alcohol and feelings similar to intoxication in abstinent alcoholics $[5,6])$. This relates well to animal studies, where TFMPP administration (a compound structurally similar to mCPP) has discriminant stimulus properties similar to low doses of alcohol [7].

Taken together, this suggests that alcohol may be used to self-medicate in patients with dysequilibrium of the serotonergic system. This hypothesis is given further support by studies showing the efficacy of serotonergic agents in the treatment of alcoholism [8-11]. The serotonin system is, however, complex, and mCPP is a relatively nonselective agent. In order to delineate further the exact mechanisms involved in alcoholism more selective agents must be used.

Sumatriptan is a selective serotonin(5HT)1D agonist. It is postulated that sumatriptan's agonism at this terminal autoreceptor increases negative feedback, creating a net effect of decreased serotonergic neurotransmission [4] In line with Verheul's model of craving [3] sumatriptan administration, by decreasing serotonergic transmission, should theoretically produce a desire to drink.

Studies of sumatriptan administration in alcohol dependent patients suggest involvement of the 5HT1D receptor. Sumatriptan stimulates the release of growth hormone (GH) and inhibits the release of prolactin in normal individuals. In both long term and newly abstinent alcoholics sumatriptan administration did not increase GH secretion, suggesting alteration at the $5 \mathrm{HT} 1 \mathrm{D}$ receptor. $[12,13]$

The 5HT1D receptor may also be associated with repetitive behaviours. In autism, increased GH response to sumatriptan was noted [14], with the severity of repetitive behaviours correlating with response. Addictive behaviours may be viewed as a type of repetitive behaviour.

Furthermore, in OCD, sumatriptan has been suggested to produce similar effects to those of $\mathrm{mCPP}$, and its administration led to exacerbation of symptoms [15], i.e loss of control over obsessive thoughts. We hypothesized that effects of sumatriptan would be similar to those of mCPP in patients with alcoholism, namely that administration of sumatriptan would potentiate obsessive craving for alcohol. Should this hypothesis be bourne out, it would point to specific involvement of the $5 \mathrm{HT} 1 \mathrm{~d}$ receptor in the pathophysiology of alcohol craving.

\section{Methods}

Fifteen patients with alcohol dependence who had undergone detoxification (4 females and 11 males) were recruited from the acute detoxification units at Tygerberg and Stikland hospitals, Cape Town, South Africa. All subjects were medically stable, with no history of cardiac disorder, and with liver enzymes less than 1.5 times the maximum laboratory range at baseline. All subjects had at least seven alcohol and benzodiazepine-free days. For 72 hours prior to the challenge, subjects adhered to a tyramine-free diet.

Informed written consent was obtained from all subjects and the ethics committee of the University of Stellenbosch approved the study. The research was carried out in accordance with the Declaration of Helsinki of the World Medical Association. During the study subjects were inpatients at the Alcohol Rehabilitation Unit at Stikland Hospital, and received ongoing psychotherapy. On completion of a 6 week program, subjects were discharged to a weekly outpatient therapy group. These measures were felt to be sufficiently containing to prevent experimentally induced relapse.

Sumatriptan (100 mg) and placebo was administered orally in cross-over fashion on 2 separate days 72 hours apart. Sumatriptan was chosen as the challenge agent as it has the least side effects of the triptans. A drawback though, is that it has poor penetration of the blood brain barrier. However, previous work $[12,13]$ has showed altered hormonal responses in alcohol dependent patients, suggesting that sufficient amounts do cross over. Furthermore, in studies of OCD and related disorders, sumatriptan is the most commonly used challenge agent. The $100 \mathrm{mg}$ dose was chosen as in previous work on OCD and OCD related disorders, $100 \mathrm{mg}$ had been shown to increase obsessions and repetitive behaviours [14,15] Both patients and raters were blind to all treatments.

Patients were assessed on the following scales at -30, 0 30, 90, 150 and 210 minutes:

1. A 6-item scale designed to rate the patient's intention to drink. (modified from [6]) Items were rated from 0 (not at all) to 4 (extremely), and included questions such as "I would like to drink alcohol" and "I intend to drink alcohol in the near future". A $6^{\text {th }}$ question, "the tablet I took this morning feels similar to alcohol" was also posed. 
Table I:

\begin{tabular}{|c|c|c|c|c|c|c|c|}
\hline & & Group & $N$ & Mean & SE Mean & $\mathrm{T}$ & $\mathrm{P}$ \\
\hline \multirow[t]{4}{*}{ Affect analog Scale } & Cross-over effect & Placebo first & 9 & 0.0 & 1.3 & -.1 .25 & 0.241 \\
\hline & & Sumatriptan first & 6 & 2.5 & 1.5 & & \\
\hline & Linear Trend effect & Placebo first & 9 & -3.7 & 1.3 & -0.91 & 0.391 \\
\hline & & Sumatriptan first & 6 & -4.5 & 1.5 & & \\
\hline \multirow[t]{4}{*}{ Intent to drink scale } & Cross Over effect & Placebo first & 9 & -2.3 & 4.5 & -0.63 & 0.54 \\
\hline & & Sumatriptan first & 6 & 0.67 & 1.7 & & \\
\hline & Linear Trend effect & Placebo first & 9 & 16.1 & 7.9 & 2.12 & 0.058 \\
\hline & & Sumatriptan first & 6 & -2.67 & 4.0 & & \\
\hline \multirow[t]{4}{*}{ Sensation Scale } & Cross Over effect & Placebo first & 9 & -6.6 & 24 & -0.66 & 0.52 \\
\hline & & Sumatriptan first & 6 & II & II & & \\
\hline & Linear Trend effect & Placebo first & 9 & -6.8 & 21 & 0.80 & 0.44 \\
\hline & & Sumatriptan first & 6 & -27.7 & 15 & & \\
\hline \multirow[t]{4}{*}{ Craving Scale } & Cross Over effect & Placebo first & 9 & -7.4 & 4.2 & -1.92 & 0.084 \\
\hline & & Sumatriptan first & 6 & 2 & 2.4 & & \\
\hline & Linear Trend effect & Placebo first & 9 & 3.6 & 5.9 & -0.37 & 0.72 \\
\hline & & Sumatriptan first & 6 & 6.3 & 4.2 & & \\
\hline
\end{tabular}

2. The Sensation Scale [16]. Items included side effects commonly produced by alcohol, such as nausea, facial flushing, dizziness and numbness. Items were rated from 0 (not at all) to 10 (a great deal).

3. A 13-item affect analog scale designed to rate the pattern and extent of emotional changes[17].

4. An 8-item scale designed to rate the patient's craving for alcohol. Items included "I crave a drink right now" and "I want a drink so bad I can taste it". [18]

Statistical analyses were carried on out the total score for each questionnaireas well specific variables of interest. For every variable the six sequential observed scores, $\mathrm{y}_{1} \ldots \mathrm{y}_{6}$, of every subject on every occasion were summarized in two informative statistics, the sum $\mathrm{S}=\mathrm{y}_{1}+\mathrm{y}_{2}+\mathrm{y}_{3}+\mathrm{y}_{4}+\mathrm{y}_{5}+\mathrm{y}_{6}$, and the linear trend contrast $\mathrm{L}=-8 \mathrm{y}_{1}-5 \mathrm{y}_{2}-2 \mathrm{y}_{3}+\mathrm{y}_{4}+4 \mathrm{y}_{5}+10 \mathrm{y}_{6}$. Note that the weights in the $\mathrm{L}$ contrast are obtained from the first order orthogonal polynomial for the unequally spaced time intervals of observation.

Thus, for a particular variable every subject has two values of $\mathrm{S}$ one for sumatriptan and one for placebo,, say $\mathrm{S} 1$ and $\mathrm{S} 2$. , and the drug effect is measured by S1-S2. The crossover effect is measured by an estimate of the difference in location of the distribution of S1-S2 in the two groups; it can be mean(S1-S2, Group 1)-mean((S1-S2, Group2), or an estimate based on the Wilcoxon Rank Sum test; there are other possibilities, not used here. In the case of the mean the natural test statistic is of the form $\mathrm{z}=$ (difference of means)/(s.e. of the difference); note that the Welch version of the denominator was used in the calculation of $z$. The distribution of this statistic is " $\mathrm{t}$ " if the variable S1-S2 is normally distributed, with appropriate adjustment of the number of degrees of freedom for the Welch version of the ttest. In the present instance it is not, but being a difference of linear functions the distribution is symmetric, and significance levels given by the $\mathrm{t}$-distribution are robust. However, in marginal cases exact significance levels for $\mathrm{z}$ was obtained from a permutation distribution. Further, in marginal cases the Wilcoxon Rank Sum test was used for confirmation, or otherwise, of the result.

The linear effect scores, L, were analysed in the same way as the $\mathrm{S}$ scores.

\section{Results}

All but 2 measures showed no significant changes (See table 1). On the variable "anxious" (item 8 of the affect analog scale) a significant cross over effect was found $(\mathrm{z}=$ -2.36, $\mathrm{p}=0.046, \mathrm{df}=8$; exact permutation $\mathrm{P}=0.031$; Wilcoxon Rank Sum test $P=0.023$ ). In the group that received sumatriptan first the mean S1-S2 was negative, in the group that received placebo first it was positive. Neither mean differs clearly significantly from zero. In the placebo first group the signficance level attained was 0.08 . (See table 2)

On the intention to drink scale no significant mean effect was found. In the linear trend scores there is some evidence of a significant crossover effect $(\mathrm{t}=2.12, \mathrm{p}=0.058$, $\mathrm{df}=11$; exact permutation $\mathrm{P}=0.075$; Wilcoxon Rank Sum test $P=0.059)$. Further analysis showed that no significant difference in linear trend was found for the group that received sumatriptan first, but in the group that received placebo first, a marginally significant linear trend 
Table 2: Cross Over Effect - variable "Anxious" on Affect Analog Scale

\begin{tabular}{llllllll}
\hline & & Group & $N$ & Mean & SE Mean & T & P \\
\hline "Anxious" & Cross-over effect & Placebo first & 9 & -0.67 & 0.33 & \\
& & Sumatriptan first & 6 & 0.83 & 0.54 & -2.36 & 0.046 \\
& & & & & \\
\hline
\end{tabular}

Table 3: Linear Trend - Intent to Drink Scale

\begin{tabular}{|c|c|c|c|c|c|c|c|}
\hline & & Group & $N$ & Mean & SE Mean & $\mathrm{T}$ & $\mathrm{P}$ \\
\hline \multirow[t]{2}{*}{ Intent to drink } & Linear Trend effect & Placebo first & 9 & 16.1 & 7.9 & 2.039 & 0.04 \\
\hline & & Sumatriptan first & 6 & -2.67 & 4.0 & -.066 & 0.53 \\
\hline
\end{tabular}

effect was noted $(\mathrm{t}=2.039$, two-sided $\mathrm{p}=0.07$, one-sided $\mathrm{p}=0.04)($ See table 3$)$

\section{Discussion}

Our results show that overall sumatriptan has no significant ability to provoke alcohol lsymptoms or to cause a desire or craving for alcohol. The significant placebo effect on the variable "anxious" may merely represent normal anxiety when confronted with an unfamiliar task. This is made especially plausible by the fact that it only occurs in the group that took placebo first, suggesting that as patients become more familiar with the trial the anxiety disappears.

The interpretation of the linear trend on the intention to drink scale in patients who received placebo first is more difficult. On its own this suggests that sumatriptan did cause changes not seen with placebo. However, if this was true, one would also expect to find a significant linear trend in the group who received sumatriptan first. Furthermore, a significant overall drug effect should have been found. It is more plausible that the trend found is due either to error introduced by the small group size and multiple tests, or by factors unrelated to sumatriptan within the group.

The general lack of efficacy of sumatriptan in producing alcohol-like symptoms or a desire to drink alcohol may suggest that the $5 \mathrm{HT} 1 \mathrm{D}$ receptor plays little role in the pathophysiology of alcoholism. This is in contrast to studies that show decreased GH response to sumatriptan administration in abstinent alcoholics.

However, several limiting factors must be borne in mind. Firstly, the sample size was small and consisted of recently detoxified alcoholics. Chronic use of alcohol may alter the neurochemical milieu and provide a false picture of receptor involvement in alcoholism [1].

Secondly, sumatriptan has poor penetration of the bloodbrain barrier, and its failure to provoke a response may be a result of this, rather than lack of involvement of the 5 HT1D receptor in the pathogenesis of alcoholism. However, given that previous work has shown hormonal (in alcohol dependence) $[12,13]$ and behavioural (in OCD) responses [15], this is less likely.

Furthermore, it may be that GH response to sumatriptan does not necessarily correlate with behavioural changes. In OCD, there have been conflicting reports about symptom exacerbation following sumatriptan challenges, yet a decreased GH response is observed. It is possible that GH release is mediated via different pathways to behavioural effects. This is suggested by the finding in autism, where increased GH release correlated with severity of repetitive behaviours. As both OCD and alcohol dependence can be conceptualized as repetitive behaviours, this contrasts with findings in these disorders.

Finally, the majority of the sample (11 patients) had late onset alcohol dependence (age of onset > 25) using the von Knorring criteria [19]. George et al [20] found ethanol -like responses to $\mathrm{mCPP}$ were only found in the early onset group. It is possible that we did not observe a response in our sample as most had late onset alcohol dependence.

\section{Conclusion}

While our study suggests that the 5HT1D receptor does not play a significant role in the pathogenesis of alcoholism, further studies with sumatriptan and with agents that have better blood-brain barrier penetration are needed in 
both alcohol dependant and non-alcohol dependent samples to consolidate this finding. Stratification of further samples into early and late onset alcohol dependence may also be of use.

\section{Competing interests}

The author(s) declare that they have no competing interests.

\section{Authors' contributions}

$\mathrm{BV}$ participated in the statistical analysis and prepared the manuscript for publication. CJH participated in the study design and carried out the patient ratings. WP participated in the preparation of the manuscript. JSM performed the statistical analysis. DJS conceived of the study, participated in the study design and participated in the preparation of the manuscript.

\section{Acknowledgements}

The authors would like to thank Mimi Roberts for her help in patient recruitment. Bavanisha Vythilingum, Charmaine Hugo and Dan Stein are supported by the Medical Research Council of South Africa.

\section{References}

I. LeMarquand D, Pihl RO, Benkelfat C: Serotonin and alcohol intake, abuse, and dependence: clinical evidence. Biological Psychiatry 1994, 36:326-227.

2. LeMarquand D, Pihl RO, Benkelfat C: Serotonin and alcohol intake, abuse, and dependence: findings of animal studies. Biological psychiatry 1994, 36:395-421.

3. Verheul R, van den Brink W, Geerlings P: A three-pathway psychobiological model of craving for alcohol. Alcohol Alcohol 1999, 34(2): 197-222.

4. Davidson C, Stamford JA: Evidence that 5-hydroxytryptamine release in rat dorsal raphe nucleus is controlled by 5-HTIA, 5-HTIB and 5-HTID autoreceptors. Br J Pharmacol 1995, I I 4:1 I07-II09.

5. Benkelfat C, Murphy DL, Hill JL, George DT, Nutt D, Linnoila M: Ethanol-like properties of the serotonergic partial agonist $\mathbf{m}$ chlorophenylpiperazine in chronic alcoholic patients. Archives of General Psychiatry 1991, 48:333.

6. Krystal JH, Webb E, Cooney N, Kranzler HR, Charney DS: Specificity of ethanol-like effects elicited by serotonergic and noradrenergic mechanisms. Archives of General Psychiatry 1994, 5 I:898-9II.

7. Signs SA, Schechter MD: The role of dopamine and serotonin receptors in the mediation of the ethanol interoceptive cue. Pharmacol Biochem Behav 1988, 30:55-64.

8. Naranjo CA, Sullivan JT, Kadlec KE, Woodley-Remus DV, Kennedy G, Sellers EM: Differential effects of viqualine on alcohol intake and other consummatory behaviors. Clin Pharmacol Ther 1989, 46(3):30I-9.

9. Naranjo CA, Kadlec KE, Sanhueza P, Woodley-Remus D, Sellers EM: Fluoxetine differentially alters alcohol intake and other consummatory behaviors in problem drinkers. Clin Pharmacol Ther 1990, 47(4):490-498.

10. Naranjo CA, Poulos CX, Bremner KE Lanctot KL: Fluoxetine attenuates alcohol intake and desire to drink. Int Clin Psychopharmacol I 994, 9(3): 163-72.

II. Naranjo CA, Poulos CX, Bremner KE, Lanctot KL: Citalopram decreases desirability, liking, and consumption of alcohol in alcohol-dependentdrinkers. Clin Pharmacol Ther 1992, 5I(6):729-39.

12. Vescovi PP, Coiro V: Persistence of defective serotonergic and GABAergic controls of growth hormone secretion in longterm abstinent alcoholics. Alcohol Alcohol 1997, 32(I):85-90.
13. Coiro V, Vescovi PP: Alcoholism abolishes the growth hormone response to sumatriptan administration in man. Metabolism 1995, 44( ( 2): 1577-80.

14. Novotny S, Hollander E, Phillips A, Allen A, Wasserman S, lyengar R: Increased repetitive behaviours and prolactin responsivity to oral $\mathbf{m}$-chlorophenylpiperazine in adults with autism spectrum disorders. Int J Neuropsychopharmacol 2004, 7(3):249-54.

15. Stein DJ, Van Heerden B, Wessels CJ, Van Kradenburg J, Warwick J, Wasserman HJ: Single photon emission computed tomography of the brain with Tc-99m HMPAO during sumatriptan challenge in obsessive compulsive disorder : investigating the functional role of the serotonin auto-receptor. Prog Neuropsychopharmacol Biol Psychiatry 1999, 23(6): I079-1099.

16. Maisto SA, Connors GJ, Tucker JA, McCollam JB, Adesso VJ: Validation of the sensation scale: a measure of subjective physiological responses to alcohol. Behav Res Ther 1980, 18:37-43.

17. Hollander E, Stein DJ, DeCaria CM, Cohen L, Saoud JB, Skodol AE, Kellman D, Rosnick L, Oldham JM: Serotonergic sensitivity in borderline personality disorder :preliminary findings. American Journal of Psychiatry 1994, I 5 I:277-280.

18. Bohn MJ, Krahn DD, Staehler BA: Development and initial validation of a measure of drinking urges in abstinent alcoholics. Alcoholism, Clinical and Experimental Research 1995, 19(3):600-6.

19. von Knorring A-L, Bohman M, von Knorring L, Oreland L: Platelet MAO activity as a biological marker in subgroups of alcoholism. Acta Psychiatr Scand 1985, 72:5I-58.

20. George DT, Benkelfat C, Rawlings RR, Eckardt MJ, Phillips MJ, Nutt DJ, Wynne D, Murphy DL, Linnoila M: Behavioral and neuroendocrine responsesto mchlorophenylpiperazine in subtypes of alcoholics and in healthy comparisonsubjects. Am J Psychiatry 1997, I54(I):8I-7.

\section{Pre-publication history}

The pre-publication history for this paper can be accessed here:

http://www.biomedcentral.com/1471-244X/5/31/pre pub
Publish with Bio Med Central and every scientist can read your work free of charge

"BioMed Central will be the most significant development for disseminating the results of biomedical research in our lifetime. " Sir Paul Nurse, Cancer Research UK

Your research papers will be:

- available free of charge to the entire biomedical community

- peer reviewed and published immediately upon acceptance

- cited in PubMed and archived on PubMed Central

- yours - you keep the copyright 